\title{
Research
}

\section{Baltic Herring Fisheries Management: Stakeholder Views to Frame the Problem}

\author{
$\underline{\text { Päivi Haapasaari }}^{1}, \underline{\text { Samu Mäntyniemi }}^{1}$, and $\underline{\text { Sakari Kuikka }}^{1}$
}

\begin{abstract}
Comprehensive problem framing that includes different perspectives is essential for holistic understanding of complex problems and as the first step in building models. We involved five stakeholders to frame the management problem of the Central Baltic herring fishery. By using the Bayesian belief networks (BBNs) approach, the views of the stakeholders were built into graphical influence diagrams representing variables and their dependencies. The views of the scientists involved concentrated on biological concerns, whereas the fisher, the manager, and the representative of an environmental nongovernmental organization included markets and fishing industry influences. Management measures were considered to have a relatively small impact on the development of the herring stock; their impact on socioeconomic objectives was greater. Overall, the framings by these stakeholders propose a focus on socioeconomic issues in research and management and explicitly define management objectives, not only in biological but also in social and economic terms. We find the approach an illustrative tool to structure complex issues systematically. Such a tool can be used as a forum for discussion and for decision support that explicitly includes the views of different stakeholder groups. It enables the examination of social and biological factors in one framework and facilitates bridging the gap between social and natural sciences. A benefit of the BBN approach is that the graphical model structures can be transformed into a quantitative form by inserting probabilistic information.
\end{abstract}

Key Words: Bayesian beliefnetworks; influence diagrams; objectives; participatory modeling; problem framing; stakeholders; structural uncertainty

\section{INTRODUCTION}

In recent years, the complexity of fisheries systems has been acknowledged increasingly (Garcia and Charles 2007, 2008). This has led to the questioning of conventional biological stock assessments as the basis for fisheries management (Hammond and O'Brien 2001, Schnute and Richards 2001, Degnbol and McCay 2007, Kraak et al. 2010) and to proposals to expand the knowledge base toward a more holistic approach by incorporating interactions with other species, ecosystem characteristics, and socioeconomic issues (Schnute and Richards 2001, FAO 2003, Garcia and Charles 2007, CEC 2008). For this purpose, approaches need to be developed that allow the crossing of disciplinary lines, perspectives, forms of knowledge, and scales (Degnbol and McCay 2007, Garcia and Charles 2007, 2008).

We emphasize the significance of adequate problem identification and framing at the outset of a policy process. Problem framing implies that the most important elements and interrelationships within a system will be included in considerations. It thereby facilitates the understanding of the problem in its entirety, helps in identifying the right questions to be answered, and denotes the first steps in developing holistic knowledge, research, and management strategies (De Young et al. 1999, Walker et al. 2003, van der Sluijs et al. 2005a, Clark and Stankey 2006, Verweij and van Densen 2010).

A proper problem framing involves all relevant stakeholders and turns attention to the socially constructed character of management problems (Berger and Luckmann 1967, PahlWostl 2007). It goes beyond values and interests and incorporates stakeholders' perceptions and lines of reasoning (Clark and Stankey 2006, Jones et al. 2011). Different understandings of reality underlie the difficulties in management discussions; thus, making explicit how different individuals or groups piece together a problem can facilitate reciprocal learning, lead to better communication, and help to develop more effective management mechanisms (Clark and Stankey 2006, Verweij and van Densen 2010, Jones et al. 2011).

The JAKFISH project (EU FP7/2007-2013/212969, Judgement and Knowledge in Fisheries Involving Stakeholders) provided a context to involve stakeholders to frame the problem of the Central Baltic Sea herring fishery management. The main objective of JAKFISH was to develop institutions, practices, and tools that allow complexity and uncertainty to be dealt with effectively in participatory decision-making processes (Röckmann et al. 2012). In our case study, we used Bayesian belief networks (BBNs) to study systematically how different stakeholders conceive the management problem of the herring fishery and what kind of causalities involve the different views (reported here), and to elicit the causal assumptions of the stakeholders on factors that influence the natural mortality, growth, and egg survival of this herring stock in probabilistic terms (Mäntyniemi et al. 2009a). In that phase of the case study (Mäntyniemi et al $2009 a$ ), the outcome of the modeling was a set of probability 
models each describing the views of an individual stakeholder, which were then integrated using the Bayesian model averaging technique and conditioned by stock assessment data. Such a model can be used to give management advice that includes the views of the interviewed stakeholders weighted according to the correspondence of the different views with the observed data. The individual stakeholder views can also be analyzed separately to find out whether they imply different management strategies. Overall, our case study provides a holistic approach to the structural uncertainty around the Central Baltic herring fishery, i.e., it addresses the alternative causalities inherent in the fishery system.

BBNs provide a comprehensive tool for environmental risk and decision analysis (Varis and Kuikka 1999, Kuikka et al. 2011). They enable the linking of several risk factors and their management options in one model as well as examination of their impact on each other in both qualitative and quantitative terms (Shachter 1987, Spiegelhalter et al. 1993). We have previously applied BBNs to fish stock assessments and other environmental problems also involving decision analyses (Kuikka et al. 1999, 2011, Varis and Kuikka 1999). We have also found the approach useful in examining the human perspective of fisheries problems (Haapasaari et al. 2007, Haapasaari and Karjalainen 2010, Levontin et al. 2011). We have built BBN models based on expert knowledge (Kuikka and Varis 1997), but we have not, until now, tested the methodology in processes involving diverse stakeholder groups.

Here, we combine the Bayesian approach with stakeholder views to frame the management problem of the Central Baltic herring fishery. Our aim is threefold: (1) to examine both the potential and the challenges of BBNs for participatory problem framing, (2) to assess the implications of such problem framing for management, and (3) to form a basis for a follow-up study that proceeds from qualitative problem framing to quantitative model building, and to evaluate the value of different types of information needed for a holistic model (Mäntyniemi et al. 2009b).

\section{CENTRAL BALTIC HERRING FISHERY}

The Central Baltic herring fishery provides a topical case study. Assessments indicate that the spawning stock biomass (SSB) of the stock was high in the 1970s but declined until 2001, and has been below the long-term average since the beginning of the 1990s. The mean weight-at-age of individual herring has decreased considerably, by $15-45 \%$, since the 1990s, and has stabilized at a low level in recent years (ICES 2009, 2011, CEC 2010). Reasons for the herring stock's poor state are largely unknown, and scientists do not have a single agreed-upon causal structure to describe its biological productivity. The decline of the SSB is partly caused by the reduction in the growth rate of individual herring, which is believed to depend on variation in salinity, changes in the composition of the zooplankton (prey) community, and competition with sprat (ICES 2011). The herring stock is also affected by cod predation (ICES 2011).

According to ICES (2011), the stock is harvested outside of safe biological limits. Fishing is restricted by defining a yearly total allowable catch (TAC), by quotas, and by technical measures such as specifications for gear, mesh size, and fishing area. The catch goes to human consumption, fish meal, and mink farms (CEC 2010). Mixed fishing of herring with sprat causes uncertainty in reported catches and is also assumed to affect the cod stock indirectly because sprat is also a major prey of cod (ICES 2009, 2011, CEC 2010).

Currently there are no explicit single management objectives for the herring stock, but the European Commission is developing a long-term management plan (LTMP) for the pelagic stocks of the Baltic Sea, including the Central Baltic herring (CEC 2010); the overall aim is a maximum sustainable yield (MSY), as in other EU fisheries. Specific questions that have been raised in relation to the forthcoming LTMP concern, for example, cause-effect relationships in the fishery, management objectives, targets and trigger points, technical measures, adequateness of data, scientific analyses, and objectives for research. An important question is the shift from a stock-by-stock basis of management toward a fisheriesbased management approach, and further, to ecosystem-based management (CEC 2010).

\section{STRUCTURAL UNCERTAINTY}

A formal problem-framing activity is an attempt to analyze and manage the structural uncertainty inherent in a complex system. Structural uncertainty refers to the basic lack of knowledge about the components, dynamics, and internal interactions of a system (Kuikka and Varis 1997, Varis and Kuikka 1997, Charles 1998, De Young et al. 1999, Walker et al. 2003), and manifests as ambiguity, confusion, and controversy in management discussions (Charles 1998, 2001, Hammond and O'Brien 2001, Gréboval 2002).

The presence of structural uncertainty has been recognized in various aspects of management (Punt and Hilborn 1997, Charles 1998, 2001). It occurs in models, where it is denoted as the ignored or misunderstood functional relationships of the fishery system such as species structure, spatial heterogeneity, stock concentrations, migration patterns, fishfish and fish-environment interactions, fleet structure, technological change, management objectives, fishers' objectives, and fishers' responses to regulations. It occurs in the implementation of management decisions, referring to the extent to which measures can be implemented successfully because of uncertainty stemming, for example, from decisions subordinating scientific advice, lack of regulatory control, or unexpected behavioral responses of resource users. And it occurs in the interactions of institutes and people involved in the management system, i.e., how fishers and other actors 
adapt to new management institutions and how societal or management objectives are pursued in the fishery.

Structural uncertainty has largely been left aside from the standard modeling approaches, especially in quantitative terms (Charles 1998, 2001, Van der Sluijs et al. 2005a,b). There have even been doubts as to whether it is possible for structural uncertainties to be reduced over time (Charles 1998, 2001), e.g., because of constant changes in nature (Kuikka and Varis 1997). The choice of model determines the results (Kuikka and Varis 1997), which means that unaccounted structural uncertainty can cause unanticipated surprises in fishery management or lead to poor choices by decision makers (Charles 1998, 2001, De Young et al. 1999). Different risk assessment and management procedures attempt to deal with risk caused by the uncertainties in terms of the precautionary approach, but poorly defined management objectives can water down these attempts (Francis and Shotton 1997).

There is an apparent need to develop analytical methodologies to address structural uncertainty (Charles 1998, 2001). These methods should include the incorporation of different kinds of knowledge, the consideration of alternative causal structures, and the inclusion of stakeholder participation (Kuikka and Varis 1997, CEC 2002). Stakeholder participation, however, leads to an additional requirement for the methods to be interactive, understandable, and simple in a way that enables not only the participatory process, but also the feeling for stakeholders that they really see their views represented (Kraak et al. 2010).

\section{PROBLEM FRAMING THROUGH INFLUENCE DIAGRAMS}

Techniques such as conceptual content cognitive maps (Austin 1994, Kearney and Kaplan 1997); Actors, Resources, Dynamics, and Interactions (ARDI; Etienne et al. 2011), fuzzy cognitive mapping (Özesmi and Özesmi 2004), and various others have been used in participatory processes that elicit stakeholders' mental models (Fortuin et al. 2011, Jones et al. 2011). All provide tools to structure and communicate complex issues, to recognize various perspectives, and to help build shared understanding. They also have potential to guide environmental research processes and problem solving and to integrate different types of knowledge (Hukkinen 1993, 1999, Pavao-Zuckerman 2000, Heemskerk et al. 2003, Fortuin et al. 2011, Jones et al. 2011).

We used BBNs in the form of influence diagrams to involve stakeholders in framing the Central Baltic herring management problem. BBNs are directed acyclic graphical models that map out cause-effect relationships embedded in an individual's thinking, judging that certain events, actions, or factors will lead to particular outcomes. Influence diagrams are BBNs that include, in addition to uncertain variables, alternative management decisions and personal valuation of the outcomes of the management (utility, loss, or preference of the decisions); they thus can be used to represent, analyze, and solve decision problems under uncertainty. The role of the BBN in influence diagrams is to describe in a probabilistic context the uncertain causal chain from management actions to valued outcomes (Kuikka et al. 1999, Varis and Kuikka 1999, Cain 2001, Jensen 2001). Like the abovementioned mental modeling approaches, BBNs enable the explicit inclusion of salient factors and conditions and provide a framework to elicit the knowledge of experts or stakeholders (Hukkinen 1993, 1999, Kuikka and Varis 1997, Varis and Kuikka 1997, Cain 2001, Jensen 2001, Uusitalo 2007). Lynam et al. (2007) found BBNs useful for participatory modeling because they compel participants to articulate clearly the variables and their causalities.

The most important feature that makes BBNs especially advantageous as a method for stakeholder elicitation and problem framing relates to their subjective perspective to knowledge. The approach uses probability as an explicit measure of personal uncertainty, expressed in terms of the degree of belief (Spiegelhalter et al. 1993). Thus, in a problemframing approach, BBNs provide a tool to structure the diverse subjective views in a qualitative way, but they also include the possibility of developing the problem framing into quantitative risk assessment models. Further, the subjective perspective to knowledge allows combining stakeholder knowledge with knowledge acquired from data analyses, and updating prior knowledge when new information is available to obtain an a posteriori understanding of the issue (Pearl 1988, Jensen 2001, O’Hagan et al. 2006).

A basic BBN model consists of a qualitative part and a related quantitative part. The qualitative part depicts variables (propositions, attributes, issues, events) and their relationships from conditioning variable to conditioned variable. Quantifying a BBN means expressing the strengths of the relationships by joint probability distributions, where the probability expresses the degree of belief (Spiegelhalter et al. 1993, Gelman et al. 1995, Kuikka and Varis 1997, Varis and Kuikka 1997, Cain 2001, Jensen 2001). Probabilities can be elicited from stakeholders or acquired by separate studies focusing on different causal links of the network (Dennis 1996). Mäntyniemi et al. (2009a) propose Bayesian techniques to estimate the required probabilities. In problem framings and in scenario-based modeling approaches, the strength of the links can be indicated in simpler ways, e.g., by the thickness of the arrows (thicker arrows indicating stronger effects; Varis and Fraboulet-Jussila 2002, Varis and Lahtela 2002) or by the indicators positive, negative, zero, and ambiguous (Wellman 1990, Druzdzel and Henrion 1993, Renooij and van der Gaag 1998).

Previously, Varis and Kuikka (1997) focused on the structure of the model, i.e., the links between variables. In contrast, 
Kuikka et al. (1999) focused on the use of simulation results or databases to learn the required conditional probability tables. Here, we look especially at the different causal structures seen by the different actors, and therefore, the approach is closest to that used by Varis and Kuikka (1997).

\section{THE BALTIC HERRING CASE}

We invited five stakeholders from three Baltic Sea countries (Estonia, Finland, and Sweden) to frame the problem of the Central Baltic herring fishery management. We defined stakeholders broadly, including not only the resource user groups, but also environmental nongovernmental organizations (ENGOs), managers, decision makers, and scientists, because we thought all these groups had a stake in creating the knowledge base for fisheries management. Thus, when using the word stakeholder, we refer to all the actor groups that take part in discussions about fisheries issues. The basis for the selection of the individual stakeholders was that the persons had to be involved with herring fishing, management, or research, and thus be familiar with the issue. We did not assess the expertise of the participating persons beforehand, but after the workshops, they were asked to self-evaluate their knowledge of Baltic herring stocks. Two of them reported that they had a lot of knowledge about Baltic herring stocks, three reported that they had some knowledge, and none reported that they had hardly any knowledge.

One of the participants was a leading officer in a fisheries ministry, being a herring fishery policy maker (hereafter, the Manager). One was a member of an ENGO and a parliament member (the ENGO representative); his knowledge of herring was based on both his profession and his interest as an environmental activist and decision maker. One participant was a leading officer in a fisherman organization, being involved with the Central Baltic herring fishery through the members of the organization; he was a fish biologist by education (the Fisher). Two of the participants were scientists who, for many years, had been involved in the Baltic herring stock assessment group of the International Council for the Exploration of the Sea (ICES; Scientist 1 and Scientist 2). We were interested in the interpersonal variation in the views of the stakeholders; therefore, each expert was asked to frame the problem independently of the others. Each stakeholder was selected to provide his personal view as a representative of his reference group, not to represent his group, although he potentially represented the typical view of the group.

Three people were involved in each problem-framing session: the stakeholder, a modeling expert, and a social scientist observing the process and taking notes. The modeling expert acted as a facilitator, presenting the task and the questions and building the model according to the views of the stakeholder (O'Hagan et al. 2006). The interview was semi-structured (Flick 1998), such that the facilitator guided the process through asking relevant questions in an appropriate order but tried not to influence the answers. The stakeholder made all the decisions related to the problem framing, i.e., he defined the variables and the links between them based on his interests, values, and beliefs on the causal relationships. Only referential information about the task was given to the stakeholders before the workshop to prevent them from obtaining information from literature. The sessions took $4-6 \mathrm{~h}$ each.

The stakeholders were asked to identify the problem through building an influence diagram for the management of the Central Baltic herring fishery. The participants were asked three main questions: What variables and causalities should be taken into account in herring stock assessment and management? What should be the objectives for herring fishery management? What kind of management measures could or should be used to reach these objectives? The aim of the first question was to outline how the stakeholders perceived the herring fishery system with regard to its components and interrelationships. With the second question, we wanted to know what objectives the stakeholders saw important from the viewpoint of the society. The aim of the third question was to see how the preferred management measures differed between stakeholders and how they were related to the objectives and causalities. The views of the stakeholders were built into influence diagrams representing variables and their causalities. We used three types of variables: uncertain relevant variables of the fishery system (depicted as ovals), decision variables that are directly controllable (depicted as rectangles), and utility/loss/preference variables defining the objectives (depicted as diamonds). The arrows between variables were of three different thicknesses describing the assumed strength of the relationship: a thin arrow depicted a weak effect, a medium arrow a moderate effect, and a thick arrow a strong effect. The resulting influence diagrams did not include numerical information about the parameters, i.e., there were no conditional probability tables at this stage.

\section{FIVE VIEWS OF HERRING FISHERY MANAGEMENT}

\section{The core model}

The stakeholders were asked to frame the problem of herring fishery management starting from a biological core model built by scientists for the annual stock dynamics of the Central Baltic herring (Fig. 1). The model was a generic description of stock dynamics, including the basic components related to recruitment, growth, and mortality of fish, with nine variables and ten arrows depicting the assumed influences of these variables on each other.

\section{The Manager: consider economic issues}

The Manager framed the herring fishery management problem from an economic dimension (Fig. 2). In his view, the objective of herring fishery management is to ensure a stable average salary for fishers in perpetuity. The thick arrows in the right 
upper section of the network express the Manager's belief that the number of fishers, their capacity to fish, and their catch (in weight) strongly influence achieving this objective, and further, that the most effective management measures to regulate these are the TAC and the distribution of TAC among fishers. The moderate arrows show that, according to the Manager, fishing effort, fishing costs, and the price of fish have a smaller effect on achieving the objective. The Manager thinks that closing areas or seasons, as well as a TAC, restrict fishing effort effectively, but that ultimately the influence of fishing effort is not very strong in the management objective (moderate arrow). Gear regulations were not regarded as a very effective management measure (moderate arrows to fishing effort, and further, to salary for fishers). Overall, the Manager included several economic factors in the network that he believed influence the objective of retaining stable salaries for fishers such as the type of processing fish (influenced by the market situation), which has a strong effect on fish prices, and the price of fuel (conditioned by the state of the economy), which affects fishing costs. He saw these as having an effect on the whole herring management system and thus as important to be taken into account.

Fig. 1. The biological core model.

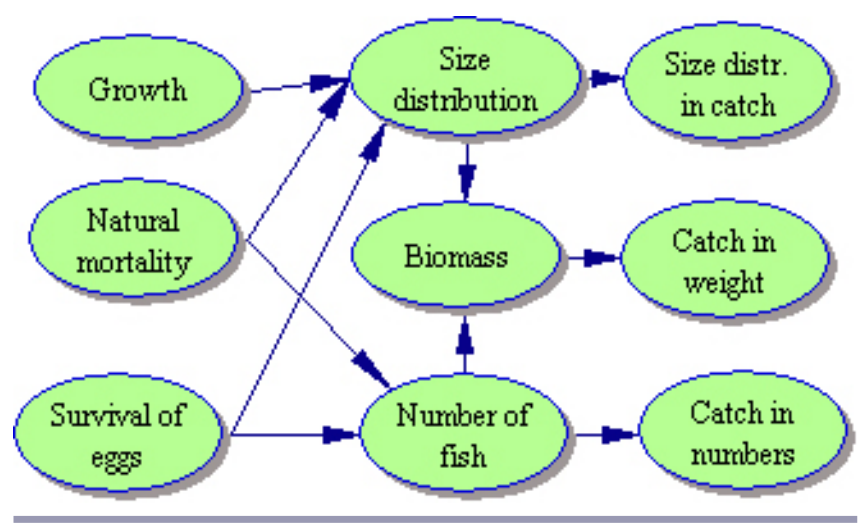

\section{The ENGO representative: balance between human} community and nature

According to the ENGO representative, the long-term objective of herring fishery management is to ensure both the viability of coastal communities depending on the fishery and the natural balance of the key species (Fig. 3). He stressed the importance of profits for the fishing communities and considered that profits are particularly influenced by fish prices (paid to fishers), fishing effort, and fishing costs, and to a lesser extent, by catch size (catch in weight, medium arrow). The ENGO representative thought that profitability could be somewhat improved by subsidies. He saw a strong link between fishing effort and catches. The ENGO representative considered that the number of fish strongly influences the number of spawning females, which is decisive for the objective of natural balance of the key species (thick arrows). He mentioned two other interlinked management objectives: herring has to be used for human consumption only, and not for technical use (e.g., fodder), and this has to be regulated by a management measure. Overall, the ENGO representative considered that management measures are a large entity of international agreements and fishery legislation and that these are very important and powerful (thick arrows). However, he also considered the influence of practical management measures weaker (medium arrows) and emphasized the importance of scientific surveys.

\section{The Fisher: ensure employment of fishers}

The Fisher set five objectives for herring fishery management and prioritized them (Fig. 4). First, ensure the employment of fishermen, both annually and in perpetuity. Second, protect the herring stock in perpetuity. Third, ensure maximum sustainable economic yield (5 yr). Fourth ensure maximum sustainable yield (5 yr). Fifth, decrease dioxin content of fish (10 yr), which is strongly related to fish size distribution in the catch. The Fisher considered the demand and price of fish as very important in achieving the economic objectives (thick arrows). He saw TAC and restricting days at sea to be very effective measures in regulating catches and ensuring fishers' employment, and emphasized the significance of surveys (thick arrows). The Fisher also regarded sprat management as very important because it influences the fishing mortality of herring (thick arrows). He also believed that cod influences the natural mortality of herring.

\section{Scientist 1: natural processes}

Scientist 1 considered three objectives for herring management and also prioritized them (Fig. 5). First, ensure that there are enough herring in the sea in terms of both biomass and numbers (thick arrows). This implies that both the mean size of fish and their abundance play a role in setting the objective. Second, ensure that the herring comprise a food source for predators, including humans. Scientist 1 considered that this objective to some extent depends on the size distribution and number of fish in the sea (medium arrows). Third, ensure that the genetic diversity of the spawning population of herring endures. Scientist 1 believed this depends on how many fish there are in the sea and their size, but he saw only a weak link here. According to Scientist 1, surveys are important in herring management, especially in relation to determining the size distribution of herring. Scientist 1 suggested spatial TAC (in weight) as the only management measure restricting catches, but considered its effect weak.

\section{Scientist 2: importance of science}

Scientist 2 thought that the objective for herring fishery management is to keep the herring population at a certain level (Fig. 6). He regarded the size distribution and biomass of 
Fig. 2. The Manager's model.

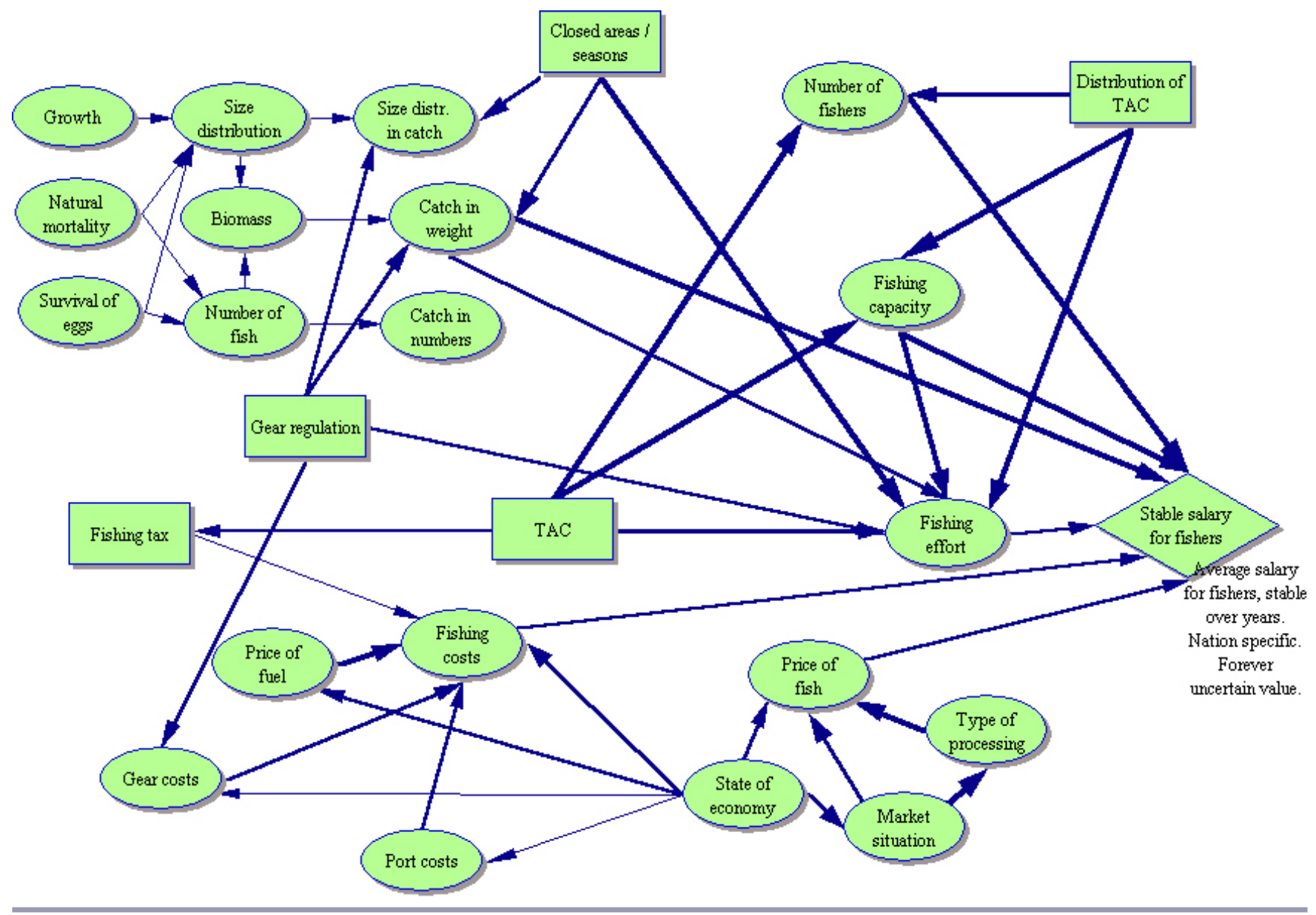

herring (thick arrow), and to a smaller extent the number of herring (medium arrow), as prerequisites for reaching this objective. According to him, the scientific surveys that update estimates of the state of the herring stock are especially important (thick arrows), whereas the importance of observing catches is weaker (medium arrows). Scientist 2 considered TAC and closures of spawning grounds as appropriate measures for restricting fishing mortality but believed that these management measures can only have a moderate influence (medium arrows). He also saw that management measures targeted on sprat and cod have roles in herring management. He considered that although cod can be managed with effective management measures, the effect of cod management on herring stocks is weak because he did not believe that cod have a strong effect on the natural mortality of herring (thin arrow). He did not believe measures for sprat to be very effective, but the influence of sprat on the growth of herring he regarded as strong. Thus, according to Scientist 2 , sprat management might have a stronger effect on herring stocks than cod management.

\section{WHAT CAN WE LEARN FROM THE INFLUENCE DIAGRAMS?}

The influence diagrams differed from each other by their content, complexity, and temporal and spatial scales. The variables of the core model were given different visibility in different problem framings, in relation to other factors that the participants found important. Some of the stakeholders added variables that in their judgment had an impact on the recruitment, growth, and mortality of herring; afterwards, the predictive probability distributions for these causalities were estimated using available data (Mäntyniemi et al., unpublished data). The scientists considered the biological stock dynamics a very central part of the management problem that they framed in biological terms. The Fisher highlighted the impact of management measures on catches, and further, on fishers' employment. In the models of the Manager and the ENGO representative, the biological core formed only a minor part of a wide holistic network; the Manager focused on economic issues, whereas the ENGO representative stressed balance between nature and society. 
Fig. 3. The ENGO representative's model.

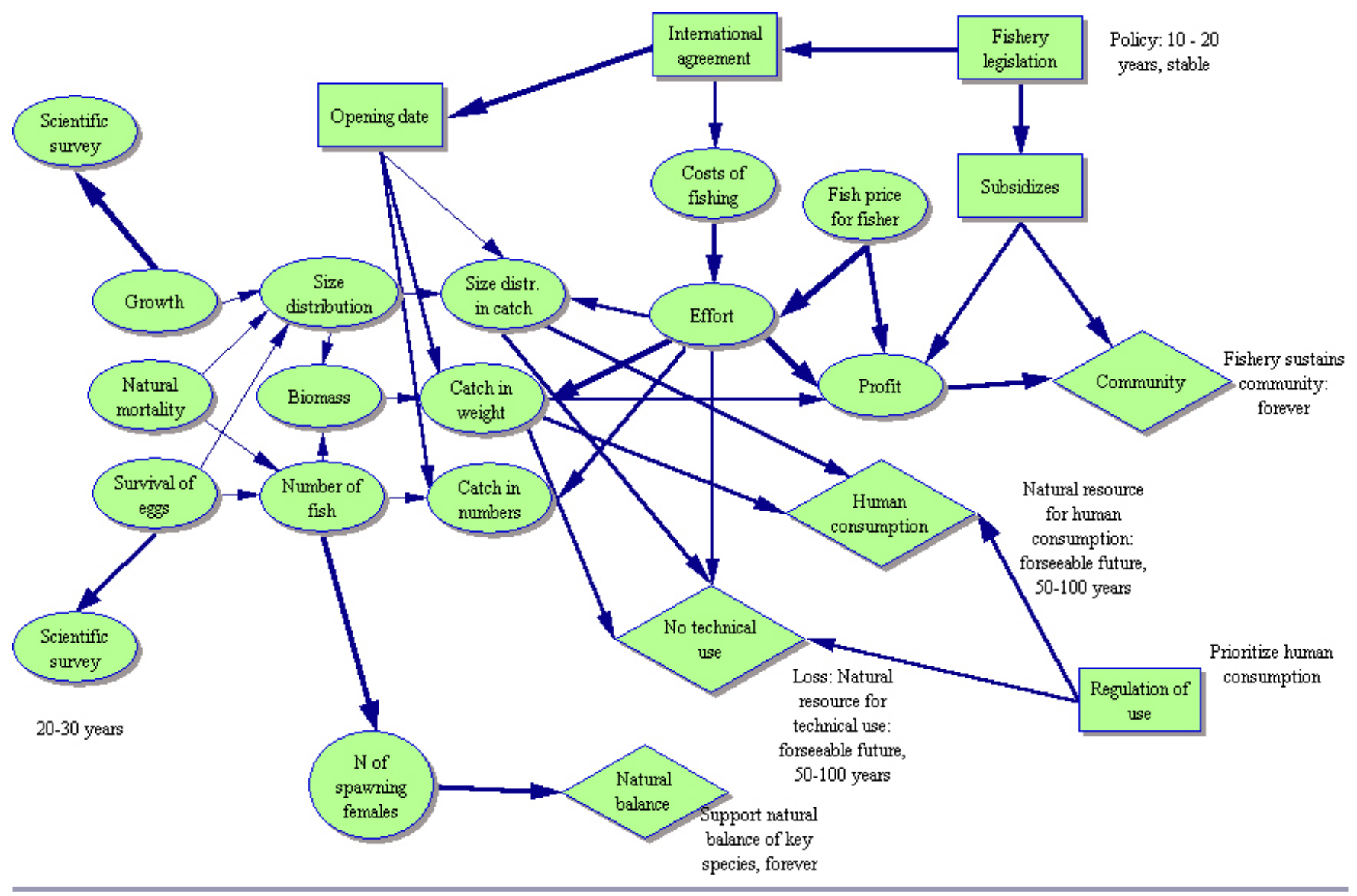

The scientists saw the management objectives in purely biological terms, whereas the others highlighted socioeconomic objectives such as incomes for fishers, sustainable human communities, employment of fishers, and maximum sustainable economic yield. This indicates a need for agreeing upon and explicitly defining objectives, not only in biological but also in social and economic terms. More specific objectives included decreasing the dioxin content in herring (Kiljunen et al. 2007), ensuring genetic diversity, and restricting the use of herring catch only to human consumption. The objectives were set in the long term, from 5 yr to in perpetuity, which indicates support for the long-term plan being designed for Baltic pelagic species.

The current management measures (TAC, quotas, technical measures) were mentioned as appropriate tools to achieve the socioeconomic objectives, but their assumed effects on the biological objectives were less clear. Overall, two of the stakeholders considered the effect of management measures to be strong in achieving objectives, whereas three of them considered their impact relatively weak. In three models, factors such as the demand and price of fish were seen as equally or even more important than regulations for reaching objectives. The impact of other species and their management on the herring fishery, especially for cod and sprat, were highlighted in two models.

Such diverse views on a management problem pose challenges to discussions between stakeholders in cases in which they need to agree on management actions or the criteria underlying decisions. It may be difficult for stakeholders to accept and commit to management measures that they believe have a weak impact on the causal chain or to measures that address objectives that they do not acknowledge.

Our study indicates that the current fisheries management procedures based on biological fisheries analyses do not cover the interests and views of all the stakeholders who were included in this analysis. It highlights the importance of putting more emphasis on social and economic issues and supports the ecosystem approach to the Central Baltic herring fishery management. Thus, our study shows that involving stakeholders that represent different perspectives in problem framing can facilitate the understanding of the broader context of fisheries. 
Fig. 4. The Fisher's model.

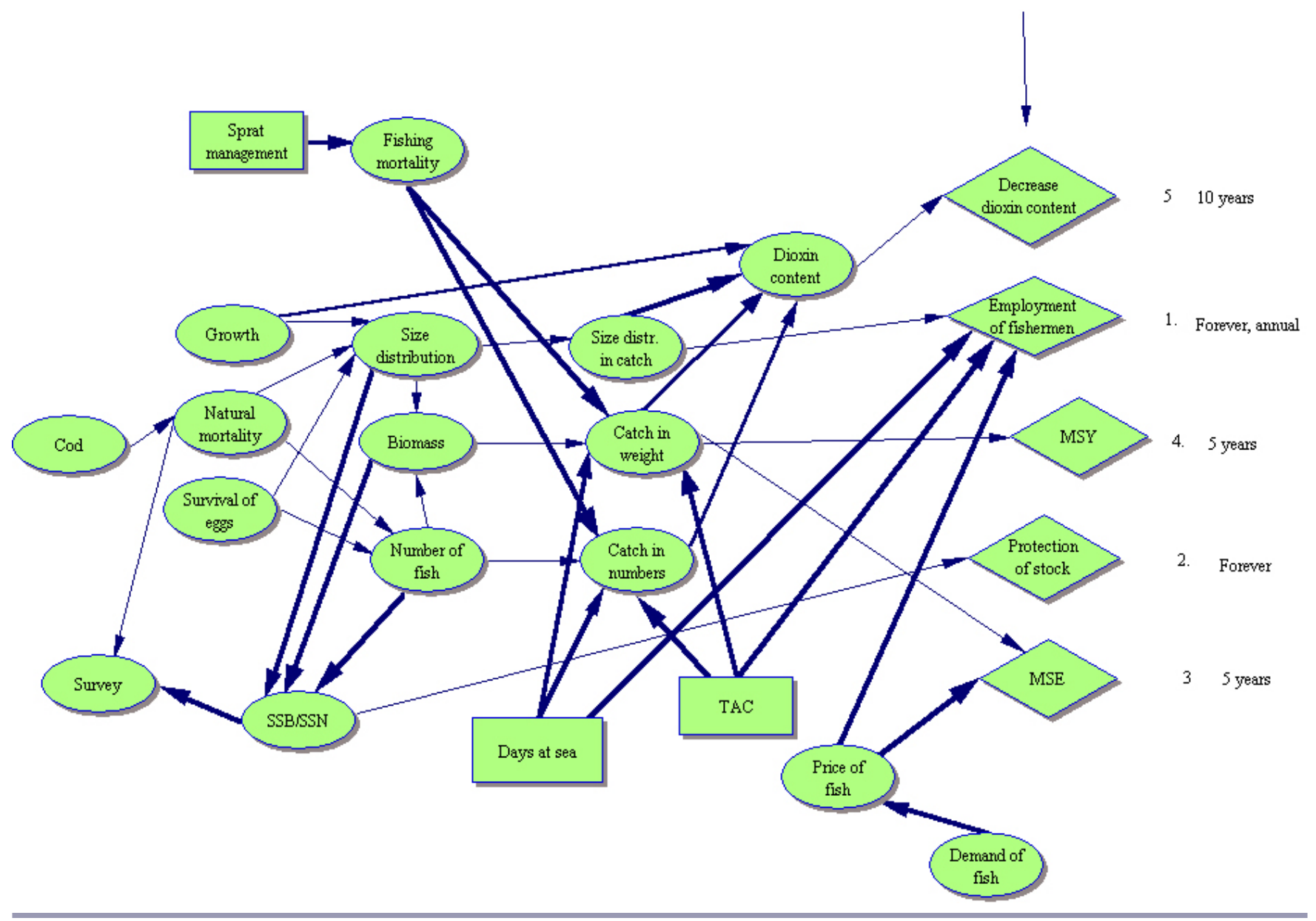

\section{REFLECTIONS ON THE BBN APPROACH}

The following issues were raised for consideration during or after the influence diagrams were constructed:

1. The stakeholders reported it difficult to decide which factors to include in their causal structures and how to set links between them but said that the graphical modeling tool facilitated the opening of the complex issue: seeing variables one by one drawn in a network of causalities refreshed their thinking.

2. Our participants regarded their skills as being critical in the problem framing. They had to be capable of relatively quick abstract reasoning (Lynam et al. 2007) and well acquainted with the herring problem. Thus, they stressed the importance of allowing stakeholders to prepare for the modeling with their reference group.

3. We invited five stakeholders to frame the problem of the herring fishery management. Here, the number of stakeholders was not critical because the main aim was to test the Bayesian approach in participatory modeling and because we did not aim to cover all possible stakeholder groups. Including other groups such as fish processors and consumers, for example, or more persons from each group might have increased the variability in the models, but would also increase the effort and cost. However, the approach allows the addition of as many problem framings by different individuals as needed to reach an appropriate variety of causal structures. If the causal structures between stakeholders representing different groups differ remarkably from each other, as they did here, it may be expected that differences in views would emerge also within the groups. This might indicate a need to further elicit different views by involving more participants from each group. We suggest additional consideration of the type and number of stakeholders to be included in the research process. The final decisions may be justified to be left to the decision makers. Overall, the Bayesian approach does not set minimum sample sizes required for analyses (Uusitalo 2007). 
Fig. 5. Scientist 1's model.

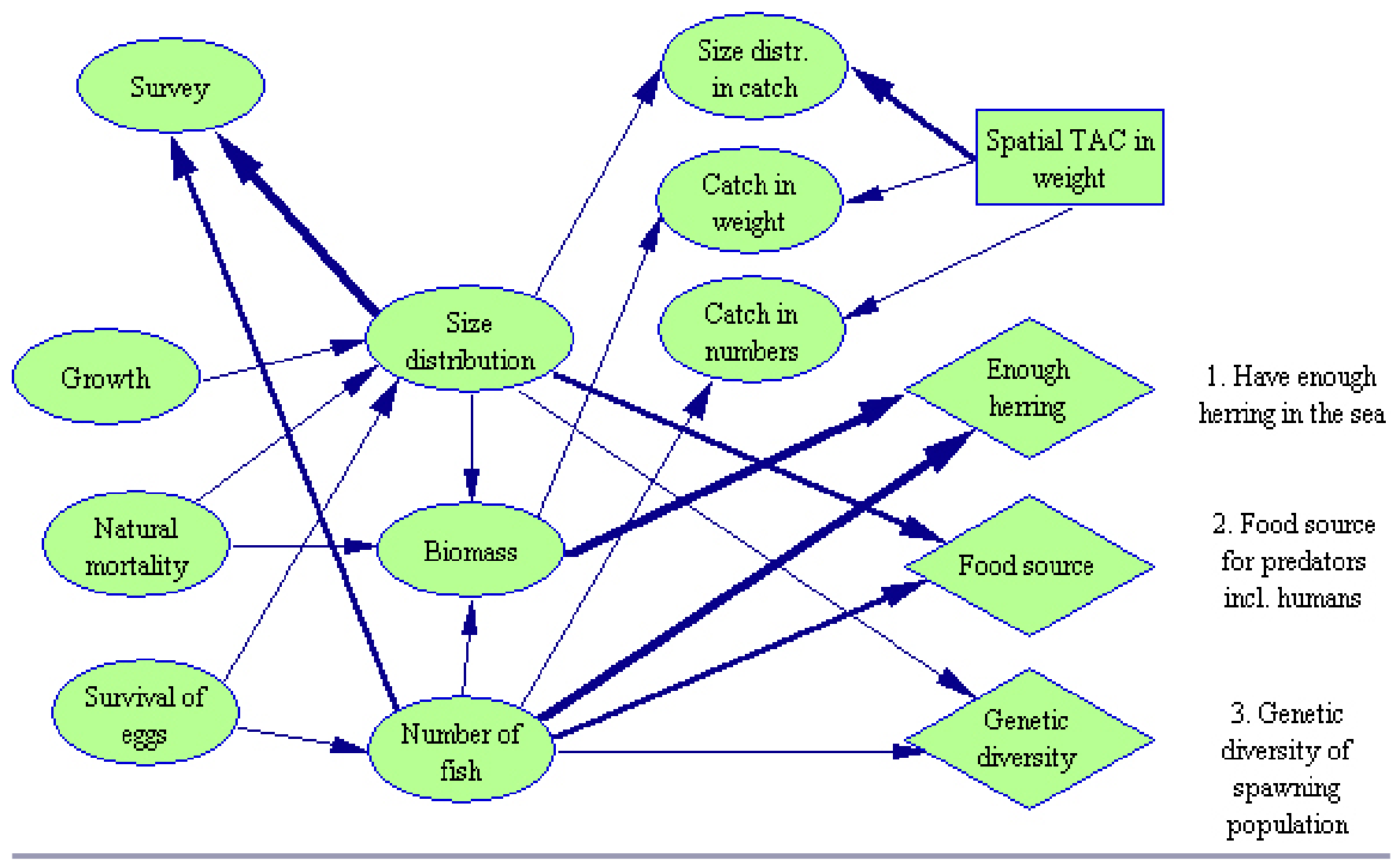

4. The core model focused on annual stock dynamics, whereas the problem framing, which included the core model as a part of the whole model, considered management measures and objective setting, which usually have a longer-term perspective. Thus, the different stakeholders framed the problem using different temporal scales varying from 1 to $100 \mathrm{yr}$ and even in perpetuity. This mismatch between the core model and the problem-framing task reflects the character of complex problems in crossing temporal and spatial scales and makes it more difficult to compare the different structures. This could be avoided by more strictly defining the time frame.

5. The decision to build the influence diagrams around annual dynamics (within-year effects) was based on an attempt toward simplicity. Although the stakeholders made many assumptions that could be articulated as an annual effect, they expressed other dependencies that could be formally presented as transitions from year to year. In particular, temporal feedbacks in the system could not be explicitly stated using the formal rules for constructing the causal networks. This problem can be avoided by presenting the graphical model as a transition from one time step to the next, which would enable more explicit modeling of feedbacks. The downside of the transition model is that it would require several copies of the annual parameters to be added to the graph, which would make the graph more difficult to read.

6. The process of constructing the graph was a challenging task for the facilitator. Some of the stakeholders learned the logic of graphical modeling very quickly and were able to give clear directions for constructing the graph. For other stakeholders, the process involved more discussion. The stakeholder expressed his views, which were then interpreted by the facilitator as nodes and arrows in the graph. After drawing new elements to the graph, the facilitator explained what the graphical structure meant to check that the view of the stakeholder was correctly implemented in the graph. In the case of wrong interpretation, the process was iterated until the stakeholder was satisfied with the meaning of the graph. Such differences between stakeholders, coupled with the communication skills of the facilitator, may have affected the results to some extent.

7. It is essential to explain the task in exactly the same way to all participants. It must be stressed, for example, 
Fig. 6. Scientist 2's model.

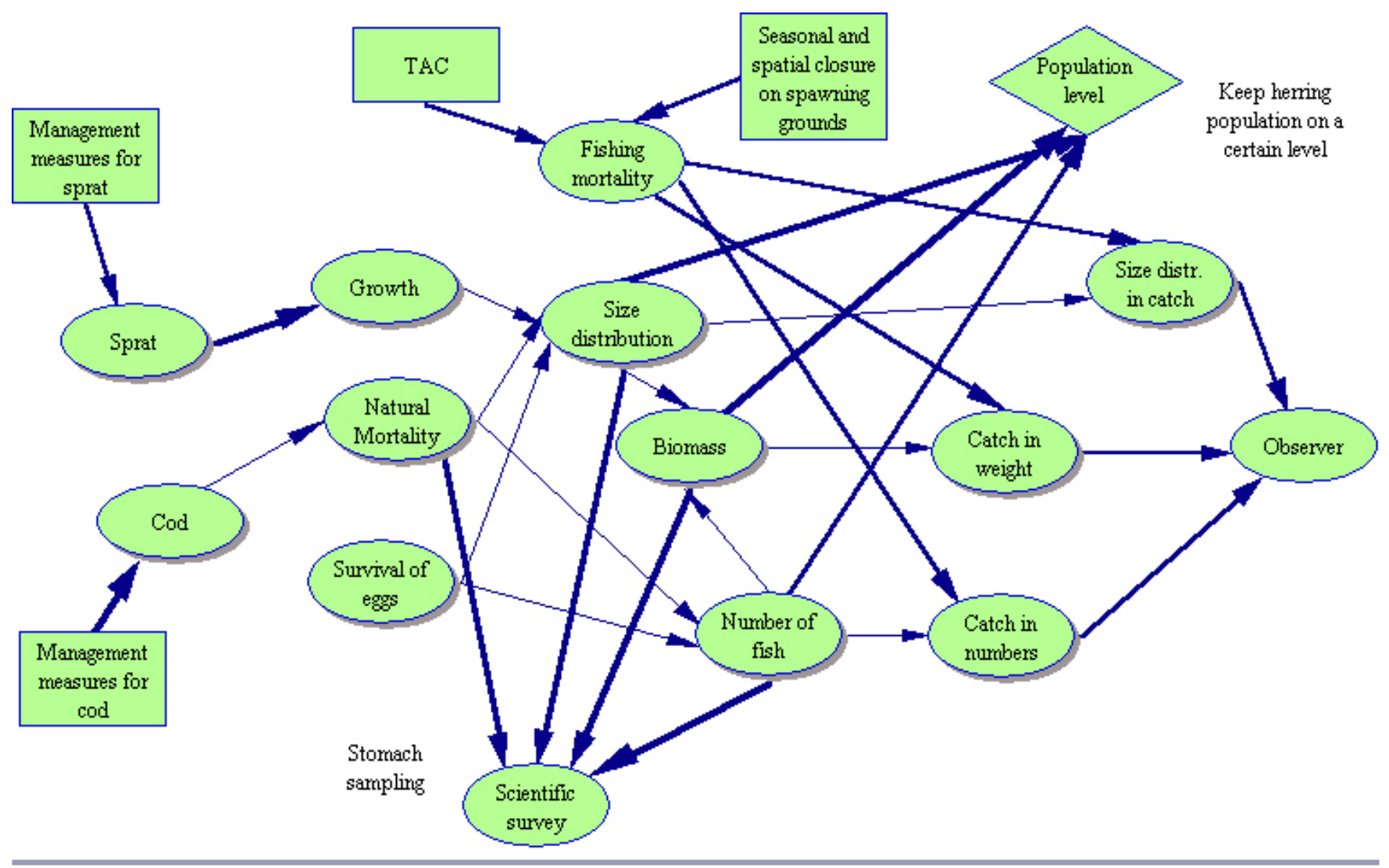

whether the stakeholder is expected to frame the problem as he/she believes it is currently, believes most of the people see it now, or believes it should be, and whether he/she is expected to express his/her own thoughts or the thoughts of the reference group. Insufficient explaining of the task may have caused the scientists to restrict their models mostly to biological causalities.

8. Although a management problem can be framed as a common task between different stakeholder groups, we suggest separate problem framings for each stakeholder group as the first step. This ensures that all the relevant issues for each group will be included, and not disturbed by interaction with another group.

\section{USABILITY OF THE BBN APPROACH FOR FISHERIES MANAGEMENT}

We found the BBN-based influence diagrams to be a useful tool for formalizing the nature of a policy problem and demonstrating different views and priorities. They are understandable and simple but still offer a basis for a considerable amount of information. They enable holistic structuring of large entities, the integration of biological questions with social and economic issues, and the explicit consideration of values in relation to assumed facts. The participatory approach addresses structural uncertainty by elaborating alternative influencing factors and causalities and thus provides a fruitful ground for the consideration of the effects of management measures on the system.

The approach turns attention to the logic of reasoning of different stakeholders. It shows what parts of a management problem the parties see similarly and where their views differ. The graphical structure of the influence diagrams makes them an illustrative basis for discussion among and between stakeholder groups and for comparing different perspectives. Enhancing the understanding of what different stakeholders think may potentially improve communication and may even facilitate finding a consensus.

In the science-policy system related to the Central Baltic herring, structural uncertainty is a critical issue that culminates in the unknown causal relations behind the low SSB and the small size of individual herring; designing an LTMP is an attempt to improve risk management related to this stock (CEC 2010). However, it is not clear what issues the LTMP should involve and what its goals should be. In such a situation, examining the assumptions and preferences of different 
stakeholders can address structural uncertainty by making explicit issues not considered before. Providing information about the diverse preferred objectives can facilitate the decision makers' task in defining management objectives and in weighting them. Explicit management objectives are a prerequisite for successful fisheries management (Francis and Shotton 1997).

Our study proposes a focus of research on the socioeconomic elements related to fisheries management. Collecting and analyzing social and economic knowledge would further enable the evaluation of the causal assumptions of the stakeholders and potentially lead to concentrating on those models that show a capability for predicting responses of the whole fishery to changes in individual factors. Decision analysis using stakeholder models could reveal the sensitivity of the scientific management advice to differences in both knowledge and objectives (Mäntyniemi et al. 2009b). This could lead to focusing research on the issues most important for successful fishery management. Assessing the value of information could propose priorities of research for policy in terms of cost-effectiveness, e.g., whether it would be more beneficial to focus on analyses of socioeconomic or biological phenomena.

The problem-framing models built by the stakeholders are instrumental as such, but the BBN approach provides the potential for them to be developed further. The models can be merged into a graphical meta-model and extended into a quantitative form by adding probabilistic information related to the strength of the links between factors. The most advanced possibility is to build an extensive meta-model of the system using the model-averaging technique (Hammond and O'Brien 2001, Mäntyniemi et al. 2009a). This would require observations to be compared with the models to weight the different models according to their correspondence with data (Mäntyniemi et al. 2009a).

Analyzing and comparing the individual stakeholder models indicates whether more stakeholder models are needed or whether a consensual meta-model can be built. A consensus model ignoring individual conflicting views might give too positive an impression about agreement between individual stakeholders. In particular, there may be a need to test how sensitive the management conclusions are in relation to the different views about multiple objectives and their relative weights. The possibility of developing a qualitative problem framing into a quantitative risk assessment model gives additional value to this approach and decreases the gap between "hard" stock assessments and "soft" humanorientated modeling.

\section{CONCLUSIONS}

The approach described here addresses structural uncertainty in terms of the alternative causal views about the relationships of key variables. It elaborates qualitative knowledge, brings into consideration issues not previously recognized, and extends understanding in a more holistic direction. In the future, we plan to develop the models further by estimating the conditional probabilities that were identified by the model structures, with each relationship quantified independently by a suitable sub-model or stakeholder knowledge, depending on the type of information available (Varis and Kuikka 1997, Borsuk et al. 2004).

The Green Paper of the European Commission (CEC 2009) on the reform of the EU Common Fisheries Policy calls for an improvement in defining policy objectives in a prioritized manner: to guide in the short term and to ensure the long-term sustainability of fisheries. Thus, the next challenge for science will be to study the prerequisites of objective setting and prioritizing: What kind of information should the objectives include to support the policy discussions? We see the problemframing approach as a step toward this new task.

Responses to this article can be read online at: http://www.ecologyandsociety.org/voll7/iss3/art36/ responses/

\section{Acknowledgments:}

The study was carried out with financial support from the European Community's Seventh Framework Programme (FP7/2007-2013) under grant agreement 212969, “Judgement and Knowledge in Fisheries Involving StakeHolders" (JAKFISH) and grant agreement 244706, "Effective use of ecosystem and biological knowledge in fisheries" (ECOKNOWS). It does not reflect the views of the European Commission and in no way anticipates the Commission's future policy in this area. We thank all the stakeholders who participated in the modeling process. We also thank Eveliina Klemola for commenting on the paper in its finalization, and the anonymous reviewers and editors for their valuable comments and suggestions.

\section{LITERATURE CITED}

Austin, D. E. 1994. Incorporating cognitive theory into environmental policymaking. Environmental Professional 16 (3):262-274.

Berger, P. L., and T. Luckmann. 1967. The social construction of reality: a treatise in the sociology of knowledge. Penguin, London, UK.

Borsuk, M. E., C. A. Stow, and K. H. Reckhow. 2004. A Bayesian network of eutrophication models for synthesis, prediction, and uncertainty analysis. Ecological Modelling 173(2-3):219-239. http://dx.doi.org/10.1016/j.ecolmodel.200 $\underline{3.08 .020}$ 
Cain, J. 2001. Planning improvements in natural resources management: guidelines for using Bayesian networks to support the planning and management of development programmes in the water sector and beyond. Centre for Ecology and Hydrology, Wallingford, UK. [online] URL: http://64.40.97.24/downloads/BBN\%20Guidelines\%20-\%20Cain. pdf.

Charles, A. T. 1998. Living with uncertainty in fisheries: analytical methods, management priorities and the Canadian groundfishery experience. Fisheries Research 37(1-3):37-50. http://dx.doi.org/10.1016/S0165-7836(98)00125-8

Charles, A. T. 2001. Sustainable fishery systems. Blackwell Science, Oxford, UK. http://dx.doi.org/10.1002/9780470698785

Clark, R. N., and G. H. Stankey. 2006. Integrated research in natural resources: the key role of problem framing. General technical report PNW-GTR-678. United States Department of Agriculture Forest Service, Washington, D.C., USA. [online] URL: http://www.fs.fed.us/pnw/pubs/pnw gtr678.pdf.

Commission of the European Communities (CEC). 2002. Council Regulation (EC) No 2371/2002 of 20 December 2002 on the conservation and sustainable exploitation of fisheries resources under the Common Fisheries Policy. Official Journal of the European Union L358:59-80. [online] URL: http://eur-lex.europa.eu/LexUriServ/LexUriServ.do?uri=OJ: L:2002:358:0059:0080:EN:PDF.

Commission of the European Communities (CEC). 2008. Communication from the Commission to the Council and the European Parliament: The role of the CFP in implementing an ecosystem approach to marine management [SEC (2008) 449]. COM(2008) 187 final. Commission of the European Communities, Brussels, Belgium. [online] URL: http://eur-le x.europa.eu/LexUriServ/LexUriServ.do?uri=COM:2008:0187: FIN:EN:PDF.

Commission of the European Communities (CEC). 2009. Green paper: reform of the Common Fisheries Policy. COM (2009) 163 final. Commission of the European Communities, Brussels, Belgium. [online] URL: http://eur-lex.europa.eu/Le xUriServ/LexUriServ.do?uri=COM:2009:0163:FIN:EN:PDF

Commission of the European Communities (CEC). 2010. Commission non-paper: on the establishment of a multiannual plan for pelagic stocks in the Baltic Sea and the fisheries exploiting those stocks. Commission of the European Communities, Brussels, Belgium. [online] URL: http://www. bsrac.org/archive/Dokumenter/Pelagic\%20WG/150410/NonPaper\%20pelagics\%20final.pdf.

De Young, B., R. M. Peterman, A. R. Dobell, E. Pinkerton, Y. Breton, A. T. Charles, M. J. Fogarty, G. R. Munro, and C. T. Taggart. 1999. Canadian marine fisheries in a changing and uncertain world: a report prepared for the Canadian Global Change Program of the Royal Society of Canada. Canadian Special Publication of Fisheries and Aquatic Sciences 129. National Research Council of Canada, Ottawa, Canada.

Degnbol, P., and B. J. McCay. 2007. Unintended and perverse consequences of ignoring linkages in fisheries systems. ICES Journal of Marine Science 64(4):793-797. http://dx.doi.org/1 $\underline{0.1093 / \text { icesjms/fsm040 }}$

Dennis, B. 1996. Discussion: should ecologists become Bayesians? Ecological Applications 6(4):1095-1103. http://dx .doi.org/10.2307/2269594

Druzdzel, M. J., and M. Henrion. 1993. Efficient reasoning in qualitative probabilistic networks. Pages 548-553 in Proceedings of the Eleventh Annual National Conference on Artificial Intelligence (AAAI-93) (Washington, D.C., 1993). AAAI Press, Palo Alto, California, USA.

Etienne, M., D. R. Du Toit, and S. Pollard. 2011. ARDI: a coconstruction method for participatory modeling in natural resources management. Ecology and Society 16(1): 44. [online] URL: http://www.ecologyandsociety.org/vol16/iss1/ $\underline{\operatorname{art} 44 / .}$

Flick, U. 1998. An introduction to qualitative research. Sage Publications, London, UK.

Food and Agriculture Organization (FAO). 2003. Fisheries management: 2. The ecosystem approach to fisheries. FAO Technical Guidelines for Responsible Fisheries 4, Supplement 2. FAO, Rome, Italy. [online] URL: ftp://ftp.fao.org/docrep/f ao/005/y4470e/y4470e00.pdf.

Fortuin, K. P. J., C. S. A. van Koppen, and R. Leemans. 2011. The value of conceptual models in coping with complexity and interdisciplinarity in environmental sciences education. Bioscience 61(10):802-814. http://dx.doi.org/10.1525/bio.201 $\underline{1.61 .10 .10}$

Francis, R. I. C. C., and R. Shotton. 1997. "Risk" in fisheries management: a review. Canadian Journal of Fisheries and Aquatic Sciences 54(8):1699-1715.

Garcia, S. M., and A. T. Charles. 2007. Fishery systems and linkages: from clockworks to soft watches. ICES Journal of Marine Science 64(4):580-587. http://dx.doi.org/10.1093/ices $\mathrm{jms} / \mathrm{fsm} 013$

Garcia, S. M., and A. T. Charles. 2008. Fishery systems and linkages: implications for science and governance. Ocean and Coastal Management 51(7):505-527. http://dx.doi.org/10.1016/ j.ocecoaman.2008.05.001

Gelman, A., J. B. Carlin, H. S. Stern, and D. B. Rubin. 1995. Bayesian data analysis. Chapman \& Hall, London, UK. 
Gréboval, D., editor. 2002. Report and documentation of the International Workshop on Factors Contributing to Unsustainability and Overexploitation in Fisheries. Bangkok, Thailand, 4-8 February 2002. FAO Fisheries Report 672. FAO, Rome, Italy. [online] URL: ftp://ftp.fao.org/docrep/fao /005/y3684e/y3684e00.pdf.

Haapasaari, P., and T. P. Karjalainen. 2010. Formalizing expert knowledge to compare alternative management plans: sociological perspective to the future management of Baltic salmon stocks. Marine Policy 34(3):477-486. http://dx.doi.or $\mathrm{g} / 10.1016 / \mathrm{j} . \mathrm{marpol} .2009 .10 .002$

Haapasaari, P., C. G. J. Michielsens, T. P. Karjalainen, K. Reinikainen, and S. Kuikka. 2007. Management measures and fishers' commitment to sustainable exploitation: a case study of Atlantic salmon fisheries in the Baltic Sea. ICES Journal of Marine Science 64(4):825-833. http://dx.doi.org/10.1093/i cesjms/fsm002

Hammond, T. R., and C. M. O'Brien. 2001. An application of the Bayesian approach to stock assessment model uncertainty. ICES Journal of Marine Science 58(3):648-656. http://dx.doi. org/10.1006/jmsc.2001.1051

Heemskerk, M., K. Wilson, and M. Pavao-Zuckerman. 2003. Conceptual models as tools for communication across disciplines. Conservation Ecology 7(3): 8. [online] URL: htt p://www.consecol.org/vol7/iss3/art8/.

Hukkinen, J. 1993. Bayesian analysis of agricultural drainage problems in California's San Joaquin valley. Journal of Environmental Management 37(3):183-200. http://dx.doi.org /10.1006/jema.1993.1015

Hukkinen, J. 1999. Institutions in environmental management: constructing mental models and sustainability. Routledge, London, UK.

International Council for the Exploration of the Sea (ICES). 2009. 8.3.3.1 Multi-annual management of pelagic fish stocks in the Baltic. Advice 2009, Book 8. ICES, Copenhagen, Denmark. [online] URL: http://www.ices.dk/committe/acom/ comwork/report/2009/Special\%20Requests/EC\%20Multiannual\% 20management\%20pelagic\%20stocks\%20Baltic.pdf.

International Council for the Exploration of the Sea (ICES). 2011. 8.4.4 Ecoregion stock: Baltic Sea: herring in subdivisions 25-29 and 32 (excluding Gulf of Riga herring). Advice 2011, Book 8. ICES, Copenhagen, Denmark. [online] URL: http://www.ices.dk/committe/acom/comwork/ report/2011/2011/Her-2532-Ex-Go.pdf.

Jensen, F. V. 2001. Bayesian networks and decision graphs. Springer, New York, New York, USA.

Jones, N. A., H. Ross, T. Lynam, P. Perez, and A. Leitch. 2011. Mental models: an interdisciplinary synthesis of theory and methods. Ecology and Society 16(1): 46. [online] URL: http:/ /www.ecologyandsociety.org/vol16/iss1/art46/.
Kearney, A. R., and S. Kaplan. 1997. Toward a methodology for the measurement of knowledge structures of ordinary people: the conceptual content cognitive map (3CM). Environment and Behavior 29(5):579-617. http://dx.doi.org/1 $\underline{0.1177 / 0013916597295001}$

Kiljunen, M., M. Vanhatalo, S. Mäntyniemi, H. Peltonen, S. Kuikka, H. Kiviranta, R. Parmanne, J. T. Tuomisto, P. J. Vuorinen, A. Hallikainen, M. Verta, J. Pönni, R. I. Jones, and J. Karjalainen. 2007. Human dietary intake of organochlorines from Baltic herring: implications of individual fish variability and fisheries management. Ambio 36(2-3):257-264. http://dx. doi.org/10.1579/0044-7447(2007)36[257:HDIOOF]2.0.CO;2

Kraak, S. B. M., C. J. Kelly, E. A. Codling, and E. Rogan. 2010. On scientists' discomfort in fisheries advisory science: the example of simulation-based fisheries managementstrategy evaluations. Fish and Fisheries 11(2):119-132.

Kuikka, S., P. Haapasaari, I. Helle, S. Kulmala, and S. Mäntyniemi. 2011. Experiences in applying Bayesian integrative models in interdisciplinary modeling: the computational and human challenges. Pages 2135-2141 in F. Chan, D. Marinova, and R. S. Anderssen, editors. MODSIM2011, 19th International Congress on Modelling and Simulation (Perth, 2011). Modelling and Simulation Society of Australia and New Zealand. www.mssanz.org.au/modsim2 011/E9/kuikka.pdf.

Kuikka, S., M. Hildén, H. Gislason, S. Hansson, H. Sparholt, and O. Varis. 1999. Modelling environmentally driven uncertainties in Baltic cod (Gadus morhua) management by Bayesian influence diagrams. Canadian Journal of Fisheries and Aquatic Sciences 56(4):629-641. http://dx.doi.org/10.1139/ cjfas-56-4-629

Kuikka, S., and O. Varis. 1997. Uncertainties of climatic change impacts in Finnish watersheds: a Bayesian network analysis of expert knowledge. Boreal Environment Research 2(1):109-128.

Levontin, P., S. Kulmala, P. Haapasaari, and S. Kuikka. 2011. Integration of biological, economic, and sociological knowledge by Bayesian belief networks: the interdisciplinary evaluation of potential management plans for Baltic salmon. ICES Journal of Marine Science 68(3):632-638. http://dx.doi. org/10.1093/icesjms/fsr004

Lynam, T., W. de Jong, D. Sheil, T. Kusumanto, and K. Evans. 2007. A review of tools for incorporating community knowledge, preferences, and values into decision making in natural resources management. Ecology and Society 12(1): 5. [online] URL: http://www.ecologyandsociety.org/vol12/iss1/ $\underline{\operatorname{art} 5 / .}$

Mäntyniemi, S., P. Haapasaari, and S. Kuikka. $2009 a$. Incorporating stakeholders' knowledge to stock assessment: How? ICES CM 2009/O:12. ICES Annual Science 
Conference, Berlin, Germany. [online] URL: http://www.ices. dk/products/CMdocs/CM-2009/O/O1209.pdf.

Mäntyniemi, S., S. Kuikka, M. Rahikainen, L. T. Kell, and V. Kaitala. 2009b. The value of information in fisheries management: North Sea herring as an example. ICES Journal of Marine Science 66(10):2278-2283. http://dx.doi.org/10.1093/ icesjms/fsp206

O’Hagan, A., C. E. Buck, A. Daneshkhah, J. R. Eiser, P. H. Garthwaite, D. J. Jenkinson, J. E. Oakley, and T. Rakow. 2006. Uncertain judgements: eliciting experts'probabilities. Wiley, London, UK.

Özesmi, U., and S. L. Özesmi. 2004. Ecological models based on people's knowledge: a multi-step fuzzy cognition mapping approach. Ecological Modelling 176(1-2):43-64. http://dx.doi. org/10.1016/j.ecolmodel.2003.10.027

Pahl-Wostl, C. 2007. The implications of complexity for integrated resources management. Environmental Modelling and Software 22(5):561-569. http://dx.doi.org/10.1016/j.envs oft.2005.12.024

Pavao-Zuckerman, M. A. 2000. The conceptual utility of models in human ecology. Journal of Ecological Anthropology 4:31-56.

Pearl, J. 1988. Probabilistic reasoning in intelligent systems: networks of plausible inference. Morgan Kaufmann, San Mateo, California, USA.

Punt, A. E., and R. Hilborn. 1997. Fisheries stock assessment and decision analysis: the Bayesian approach. Reviews in Fish Biology and Fisheries 7(1):35-63. http://dx.doi.org/10.1023/A :1018419207494

Renooij, S., and L. C. van der Gaag. 1998. Decision making in qualitative influence diagrams. Utrecht University: Information and Computing Sciences 1998-03. [online] URL: http://igitur-archive.library.uu.nl/math/2007-0118-200212/ van der gaag 98 decision.pdf.

Röckmann, C., C. Ulrich, M. Dreyer, E. Bell, E. Borodzicz, P. Haapasaari, K. H. Hauge, D. Howell, S. Mäntyniemi, D. Miller, G. Tserpes, and M. Pastoors. 2012. The added value of participatory modelling in fisheries management - What has been learnt? Marine Policy 36(5):1072-1085.

Schnute, J. T., and L. J. Richards. 2001. Use and abuse of fishery models. Canadian Journal of Fisheries and Aquatic Sciences 58(1):10-17. http://dx.doi.org/10.1139/cjfas-58-1-10

Shachter, R. D. 1986. Evaluating influence diagrams. Operations Research 34(6):871-882. http://dx.doi.org/10.1287/ opre.34.6.871

Spiegelhalter, D. J., A. P. Dawid, S. L. Steffen, and R. G. Cowell. 1993. Bayesian analysis in expert systems. Statistical Science 8(3):219-247. http://dx.doi.org/10.1214/ss/1177010888
Uusitalo, L. 2007. Advantage and challenges of Bayesian networks in environmental modelling. Ecological Modelling 203(3-4):312-318. http://dx.doi.org/10.1016/j.ecolmodel.200 $\underline{6.11 .033}$

Van der Sluijs, J. P., M. Craye, S. O. Funtowicz, P. Kloprogge, J. R. Ravetz, and J. S. Risbey. 2005a. Combining quantitative and qualitative measures of uncertainty in model-based environmental assessment: the NUSAP system. Risk Analysis 25(2):481-492. http://dx.doi.org/10.1111/j.1539-6924.2005.00604. $\underline{\mathrm{X}}$

Van der Sluijs, J. P., M. Craye, S. O. Funtowicz, P. Kloprogge, J. R. Ravetz, and J. S. Risbey. 2005b. Experiences with the NUSAP system for multidimensional uncertainty assessment. Water Science and Technology 52(6):133-144.

Varis, O., and S. Fraboulet-Jussila. 2002. Water resources development in the lower Senegal River basin: conflicting interests, environmental concerns and policy options. Water Resources Development 18(2):245-260. http://dx.doi.org/10.1 $\underline{080 / 07900620220135085}$

Varis, O., and S. Kuikka. 1997. BENE-EIA: a Bayesian approach to expert judgment elicitation with case studies on climatic change impacts on surface waters. Climatic Change 37(3):539-563. http://dx.doi.org/10.1023/A:1005358216361

Varis, O., and S. Kuikka. 1999. Learning Bayesian decision analysis by doing: lessons from environmental and natural resources management. Ecological Modelling 119(2-3):177-195. http://dx.doi.org/10.1016/S0304-3800(99)00061-7

Varis, O., and V. Lahtela. 2002. Integrated water resources management along the Senegal River: introducing an analytical framework. Water Resources Development 18 (4):501-521. http://dx.doi.org/10.1080/0790062022000017374

Verweij, M. C., and W. L. T. van Densen. 2010. Differences in causal reasoning about resource dynamics and consequences for the participatory debate on North Sea fisheries. Marine Policy 34(6):1144-1155. http://dx.doi.org/1 $\underline{0.1016 / j . m a r p o l .2010 .03 .014}$

Walker, W. E., P. Harremoës, J. Rotmans, J. P. van der Sluijs, M. B. A. van Asselt, P. Janssen, and M. P. Krayer von Krauss. 2003. Defining uncertainty: a conceptual basis for uncertainty management in mode-based decision support. Integrated Assessment 4(1):5-17. http://dx.doi.org/10.1076/iaij.4.1.5.16466

Wellman, M. P. 1990. Fundamental concepts of qualitative probabilistic networks. Artificial Intelligence 44(3):257-303. http://dx.doi.org/10.1016/0004-3702(90)90026-V 